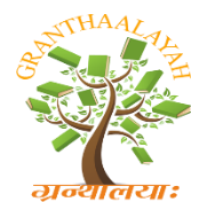

INTERNATIONAL JOURNAL OF RESEARCH GRANTHAALAYAH A knowledge Repository

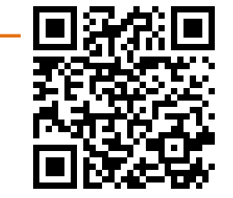

Management

\title{
EFFECT OF ORGANIZATIONAL CULTURE ON THE PERFORMANCE OF BENUE BREWERY MAKURDI BENUE STATE
}

\author{
Adamu Garba *1 \\ ${ }^{* 1}$ Department of Business Administration, Nasarawa State University, Keffi, Nasarawa State, \\ Nigeria
}

\begin{abstract}
This study examined the effect of organizational culture on performance of Benue Brewery in Makurdi. The population of this study is made up of 214 employees of Benue Brewery Limited Makurdi. Using the census approach, the population of 214 was adopted as the sample for the study. The data for the study was collected by the use of structured questionnaire while the hypotheses for the study were tested using regression analysis. The researcher found a positive effect of constructive organizational culture on profitability and market share. The result also shows a positive effect of passive organizational culture on both profitability and market share. Finally, the result also shows a positive effect of aggressive organizational culture on market share. The study concludes that the elements of organizational culture can affect the performance of an organization. It therefore recommended that management should promote constructive and passive organizational culture since these types of organizational culture have the highest influence on organizational performance.
\end{abstract}

Keywords: Organizational; Culture; Performance; Brewery; Benue; Nigeria.

Cite This Article: Adamu Garba. (2020). "EFFECT OF ORGANIZATIONAL CULTURE ON THE PERFORMANCE OF BENUE BREWERY MAKURDI BENUE STATE." International Journal of Research - Granthaalayah, 8(2), 264-271. .

\section{Introduction}

The greatest role that a manager of any firm can play is the ability to manage the human resource from diverse background. The ability to do this also keeping in mind the kinds of talent inherent in the employees is also one of the most challenging aspect of human resource management. Converging a multiplicity of employees in one company and working together to achieve the same goals has always generated concerns which every organization is poised to address. Empirical literature presents a nexus between organizational culture and performance at workplace (Rashid et al, 2013). However, Lewis (2014) concludes that behaviour is the only thing that can directly affect an organization's performance. This is because, according to the researcher, while behaviour may be one embodiment of culture, culture is certainly not the only determinant of behaviour. For an organization to survive in a harsh and competitive business environment, unexpected change in 
production processes, employees have to be adequately managed so as to improve the performance of the organization. Employees, who know what to do and desire to do them without being told, are in high demand. At workplace, employees who are proactive and can work with little or no supervision care always sought after by management (Denison and Mishra, 2003). In order to compete in the highly competitive marketplace, firms changes the way in which they carry out their functions to reflect the current reality thus producing in the worker, a state of the mind and how they go about execution of the day to day activities. This way of life (culture) could be in how customers are treated, how new product and processes are treated in line with the vision and mission of the organization. This adjustment does not actually go down well with all the staff as many persons are averse to change. Resistance to change creates a hostile atmosphere at workplace that is not favourable to the mission of the organizations

New changes bring in new technologies, new ways of doing things, new management structures. It also brings the fear of redundancy among others. While these changes reflect shifts in the culture of any organization, it is argued that a culture change if not well managed can sometimes lead to high employees' turnovers (Stafford and Miles, 2013). The foregoing fear by employees can also be attributed as the fallout of implementation of change in many manufacturing organization in Nigeria. This study seeks to determine the effect of the components of organizational culture and organizational performance. The main objective of this study is to assess the effect of organizational culture on performance of Benue State. The specific objectives however are: To examine the effect of constructive organizational culture on organizational profitability, to examine the effect of constructive organizational culture on market share, to determine the effect of passive organizational culture on organizational profitability, to assess the effect of passive organizational culture on the market share, to assess the effect of aggressive organizational culture on organizational profitability and to determine the effect of aggressive culture the market share.

\section{Literature Review}

\subsection{Conceptual Framework}

\section{Organizational Culture}

Culture is defined as a set of understandings or meanings shared by a group of people that are largely tacit among members and are clearly relevant and distinctive to the particular group which are also passed on to new members (Lewis (2014). A system of knowledge, of standards for perceiving, believing, evaluating and acting that serve to relate human communities to their environmental settings (Allaire and Firsirotu, 2014). Cooke (1996) categorized culture into three group namely; constructive culture, passive culture and aggressive culture.

\section{Concept of Performance}

Performance has been perceived differently by various researchers, but most of the scholars relate performance with measurement of transactional efficiency and effectiveness towards organizational goals (Stannack, 2006). It refers to the ability to execute a specific task in the specific manner that can be measured as high, medium or low in scale. To achieve sets targets in an organization, organizational strategies to achieve such must be put in place by the management or the board that sets up such organization. 


\subsection{Theoretical Basis}

\section{Social Identity Theory}

Social Identity Theory (SIT) was propounded by Henri Tajfel in 1974 and developed from Tajfel's work on intergroup processes which focused on the genesis of conflict between social groups, and the factors which influence support for, or attempts to change, established social hierarchies (Tajfel, 1974). According to this perspective, group membership provides people with a sense of their distinct place in the social world (where they stand in relations to others) and acts as a practical guide to action by imparting the norms concerning the typical, appropriate or desirable forms of behaviour associated with a particular group membership.

\section{Research Methodology}

\section{Research Design}

A survey design was adopted for the purpose of this study. The use of survey method also facilitates the collection of detailed factual and accurate primary data. The census sampling technique was utilized to determine the respondents for data analysis. The sample population for this study consists of all staff of Benue Brewery. As such, a sample size of 214 respondents was determined using the census technique.

\section{Study Population}

The research population includes all staff of Benue Brewery Ltd which consists of a total of 214 employees. This research will deals with all the staff because it is focusing on the effect of organizational culture on performance.

Table 1: Staff of Benue Brewery According to Department

Source: Field Survey, 2019.

\begin{tabular}{|l|l|l|}
\hline S/No & Department & Number \\
\hline 1. & Accounting & 69 \\
\hline 2. & Production & 44 \\
\hline 3. & Personnel Department & 37 \\
\hline 4. & Marketing Department & 64 \\
\hline & Total & $\mathbf{2 1 4}$ \\
\hline
\end{tabular}

The data for the study was collected using questionnaire and analyzed using the Statistical Package for Social Sciences (SPSS version 20.0). The validity and the reliability of the instrument was established using the factor analysis.

Table 2: Reliability Statistics

\begin{tabular}{|c|c|}
\hline Variables & Cronbach's Alpha \\
\hline PFT & .729 \\
\hline MKS & .804 \\
\hline COC & .874 \\
\hline POC & .809 \\
\hline AOC & .733 \\
\hline
\end{tabular}

Source: SPSS Result, 2019 
Reliability test using Cronbach Alpha was performed to measure the internal reliability of the individual variables and it was found that Organizational profitability (PFT) has a reliability of 0.729; Market Share (MKS) has a reliability of 0.804; Constructive Organizational Culture (COC) has a reliability of 0.874 , Passive Organizational Culture (POC) has a reliability of 0.809 . Aggressive Organizational Culture has a reliability of 0.729 . As shown by the individual Cronbach Alpha Coefficient the entire construct above falls within an acceptable range for a reliable research instrument of 0.70. The Cronbach Alpha for the individual variables was found to be above the limit of acceptable degree of reliability for research instrument.

\section{Models Specification}

Guided by the functional relationship between the variables of the study, the model is expressed in implicit and explicit function as shown below:

\begin{tabular}{|c|c|c|c|}
\hline $\mathrm{PFT}=\mathrm{f}(\mathrm{COC})$ & - & & (1) \\
\hline $\mathrm{MKS}=\mathrm{f}(\mathrm{COC})$ & - & & (2) \\
\hline PFT = f (POC) & - & & (3) \\
\hline $\mathrm{MKS}=\mathrm{f}(\mathrm{POC})$ & - & & (4) \\
\hline $\mathrm{PFT}=\mathrm{f}(\mathrm{AOC})$ & - & & (5) \\
\hline $\mathrm{MKS}=\mathrm{f}(\mathrm{AOC})$ & - & & (6) \\
\hline \multicolumn{4}{|c|}{$\begin{array}{l}\text { where } \\
\text { PFT = Organizational Profitability } \\
\text { MKS = Market Share } \\
\text { COC = Constructive Organizational Culture } \\
\text { POC = Passive Organizational Culture } \\
\text { AOC = Aggressive Organizational Culture }\end{array}$} \\
\hline
\end{tabular}

In explicit form, the functional relationship between the variables of the study can be shown below:

$\begin{array}{ll}\text { PFT }=b 0+b 1 C O C+U t & - \\ M K S=b 0+b 1 C O C+U t & - \\ \text { PFT }=b 0+b 1 P O C+U t & - \\ M K S=b 0+b 1 P O C+U t & - \\ P F T=b 0+b 1 A O C+U t & - \\ M K S=b 0+b 1 A O C+U t & -\end{array}$

where,

b0 = Regression constant

b1 = coefficients of independent variables.

$\mathrm{Ut}$ is the error term

\section{A Priori Expectations}

(X_1) = constructive organizational culture; a priori expectation is \pm

Multiple regression analysis was used to assess the nature and degree of relationship between the dependent variable and a set of independent or predictor variables. However, the probability value of the estimates will be used to test the 3 hypotheses of this study. 
Decision Rule: The following decision rules were adopted for accepting or rejecting hypotheses: If the probability value of bi [p (bi) > critical value] we accept the null hypothesis, that is, we accept that the estimate bi is not statistically significant at the 5\% level of significance. If the probability value of bi [p (bi) < critical value] we reject the null hypothesis, in other words, that is, we accept that the estimate b1 is statistically significant at the 5\% level of significance.

\section{Data Presentation and Analysis}

This section presents the results of the analysis of the study and the discussions.

Table 3: Regression Coefficients for the six Models of the Study

\begin{tabular}{|l|l|l|l|l|}
\hline Model & Variables & Beta & t-test & Sig level \\
\hline PFT & COC & 0.020 & 2.084 & .0340 \\
\hline MKS & COC & 0.430 & 3.867 & 0.040 \\
\hline PFT & POC & 0.071 & 4.304 & 0.005 \\
\hline MKS & POC & 0.077 & 2.239 & 0.046 \\
\hline PFT & AOC & 0.039 & 1.968 & 0.009 \\
\hline MKS & AOC & -0.499 & -2.441 & 0.025 \\
\hline
\end{tabular}

Source: SPSS 20.0 Result Output, 2019

\section{Effect of Constructive Organizational Culture on Organizational Profitability}

As shown in Table 3, a positive relationship exist between constructive organizational culture (COC) and organizational profitability (PFT) and the relationship is statistically significant $(\mathrm{p}<0.05)$ and in line with a priori expectation. This means that a unit increases in constructive organizational culture (COC) will result to a corresponding increase in the organizational profitability (PFT) by margin of $2.0 \%$. Using the probability value of the estimate, $\mathrm{p}(\mathrm{b} 1)$ < critical value at 0.05 confidence level. Thus, we reject the null hypothesis. That is, we accept that the estimate b1 is statistically significant at the $5 \%$ level of significance. This implies that constructive organizational culture has a significant on organizational profitability. In other word, the constructive organizational culture has significantly and positively increased performance in the study areas using performance proxies such as profitability. This is in line with the findings of Amah (2012) who carried out a research on corporate culture and organizational effectiveness.

\section{Effect of Constructive Organizational Culture on Market Share}

The result of the simple linear regression as shown in Table 6 show that a positive effect exist between constructive organizational culture (COC) and Market Share of the organization (MKS) and the relationship is statistically significant $(\mathrm{p}<0.05)$ and in line with a priori expectation. This means that a unit increases in constructive organizational culture (COC) will result to a corresponding increase in Market Share of the organization (MKS) by margin of $43.0 \%$. Using the probability value of the estimate, $\mathrm{p}$ (b1) < critical value at 0.05 confidence level. Thus, we reject the null hypothesis. That is, we accept that the estimate b1 is statistically significant at the $5 \%$ level of significance. This implies constructive organizational culture has a significant effect on market share of the organization. This is in line with the findings of Shahzad, Rana, Khan and Shabbir (2012) who examined impact of organizational culture on organizational performance a positive link between organizational culture and performance. 


\section{Effect of Passive Organizational Culture on Organizational Profitability}

The result of the simple linear regression as shown in Table 6 show that a positive effect exist between passive organizational culture (POC) and profitability of the organization (PFT) and the relationship is statistically significant $(\mathrm{p}<0.05)$ and not in line with a priori expectation. This means that a unit increases in passive organizational culture (POC) will result to a corresponding increase in profitability of the organization (PFT) by margin of $7.1 \%$. Using the probability value of the estimate, $\mathrm{p}(\mathrm{b} 1)<$ critical value at 0.05 confidence level. Thus, we reject the null hypothesis. That is, we accept that the estimate b1 is statistically significant at the $5 \%$ level of significance. This implies passive organizational culture has a significant effect on profitability of the organization. This finding is in line with that of Olu (2009) who analyzed and assesses empirically the impact of corporate culture on employee job performance as well as organizational productivity using Nigerian banking industry as the case study.

\section{Effect of Passive Organizational Culture on Organizational Profitability}

The result of the simple linear regression as shown in Table 6 show that a positive effect exist between passive organizational culture (POC) and market share of the organization (MKS) and the relationship is statistically significant $(\mathrm{p}<0.05)$ but not in line with a priori expectation. This means that a unit increases in passive organizational culture (POC) will result to a corresponding increase in market share of the organization (MKS) by margin of $7.7 \%$. Using the probability value of the estimate, $\mathrm{p}(\mathrm{b} 1)<$ critical value at 0.05 confidence level. Thus, we reject the null hypothesis. That is, we accept that the estimate b1 is statistically significant at the $5 \%$ level of significance. This implies passive organizational culture has a significant effect on market share of the organizations. This finding is contrary to that of Calvalluzzo and Ittner (2004) who found in their study conducted in Pakistani organizations that employees, efficiency and effectiveness were influenced by organizational appropriate culture.

\section{Effect of Aggressive Organizational Culture on Organizational Profitability}

The result of the simple linear regression as shown in Table 6 show that a positive effect exist between aggressive organizational culture (AOC) and profitability of the organization (PFT) and the relationship is statistically significant $(\mathrm{p}<0.05)$ but not in line with a priori expectation. This means that a unit increases in aggressive organizational culture (AOC) will result to a corresponding increase in organizational profitability (PFT) by margin of $3.9 \%$. Using the probability value of the estimate, $\mathrm{p}(\mathrm{b} 1)<$ critical value at 0.05 confidence level. Thus, we reject the null hypothesis. That is, we accept that the estimate b1 is statistically significant at the $5 \%$ level of significance. This implies aggressive organizational culture has a significant effect on profitability of the organizations. The findings of Farashahi, et al (2005) who conducted a study on the effects of organizational culture on staff performance found similar results.

\section{Effect of Aggressive Organizational Culture on Market Share}

The result of the simple linear regression as shown in Table 15 show that a negative effect exist between aggressive organizational culture (AOC) and market share of the organization (MKS) and the relationship is statistically significant $(\mathrm{p}<0.05)$ and in line with a priori expectation. This means that a unit increases in aggressive organizational culture (AOC) will result to a corresponding decrease in the market share of the organization (MKS) by margin of 49.9\%. Using the probability value of the estimate, $\mathrm{p}(\mathrm{b} 1)$ < critical value at 0.05 confidence level. Thus, we accept the null hypothesis. That is, we accept that the estimate b1 is not statistically significant at the $5 \%$ level of 
significance. This implies aggressive organizational culture has no significant effect on market share of the organizations. This finding is in contrary to that of Daniel et al. (2014).

\section{Conclusions and Recommendations}

\section{Conclusions}

This study found a nexus between organizational culture and performance. The link is found in the premise that organizations that focus clearly on their values and norms performed well than other organization. Several other empirical studies also have supported the positive link between organizational culture and performance. Our result linked constructive culture and passive culture with organizational performance while aggressive culture was found to be negatively related to one dimension of organizational performance - market share.

\section{Recommendations}

Based on the findings of this study, the following recommendations are made:

1) Constructive culture had the highest positive effect on organizational performance construct as shown from the result of this study. Hence, management of the company should ensure that they promote this type of organizational culture as it will lead to efficiency in the manner of interaction between management, employees and customers of the company.

2) Passive culture indicated a positive relationship with organizational performance proxied by profitability and market share. Since the characteristics o the passive culture shows executives always going along with others, always following policies and practices, pleasing those in positions of authority and waiting for others to act first, organizations must consider the negative consequences associated with passive culture and how this culture promote role stressors that promote job tension and reduced organizational performance.

3) Since aggressive organizational culture yielded both positive and negative effect on the two proxies of performance namely; profitability and market share, it is important that management of the organizations under study should encourage the aggressive organizational culture which promote the profitability of the organization such as the employees turning the job into a contest intended to outdo others which leads to higher productivity by employee.

\section{References}

[1] Allaire, Y. and Firsirotu, M.E. (2014). Theories of organizational culture. Organization Studies 5(3):6-2. Retrieved from: http://oss.sagepub.com/content/5/3/193.

[2] Amah, E. (2012). Corporate culture and organizational effectiveness. A study of the Nigerian Banking industry. European Journal of Business and Management.4 (8):212-229

[3] Calvalluzzo, H. and Ittner, O. (2004). Influence of Efficiency and Effectiveness in Pakistani Organizations. International Journal of Business Organization, 14(7):22 - 39.

[4] Cooke, E. H. (1996). Corporate Culture and Innovative performance of a firm. Management of Engineering and Technology, 2, 532-535. 
[5] Daniel, E., Wilson, H. and David, K. (2014). Adoption intentions and benefits realized: a study of ecommerce in UK SMEs, Journal of Small Businesses and Enterprise Development9(4), pp. 331348

[6] Denison, D. R. and Mishra, A. K. (2003). Toward a Theory of Organizational Culture and Effectiveness, Organization Science. 6, 204-223.

[7] Farashahi, M., Hafso, T and Molz, R. (2005). Institutionalized norms of conducting research and Social Realities: a Research Synthesis of Empirical Works from 1983 to 2002', International Journal of Management Review, 7, 1-24.

[8] Lewis, D. (2014). How Useful a Concept is Organizational Culture, Journal Strategic Change. 7(3), 261-276.

[9] Olu, O. (2009). Leadership Behaviour and Organisation Transformation: A Theoretical and Empirical Analysis, Annals - Economic and Administrative Series -, Faculty of Business and Administration, University of Bucharest, 3(1):185-199.

[10] Rashid, M. Z. A., Sambasivan, M., and Johari, J. (2013). The influence of corporate culture and organisational commitment on performance. Journal of management development, 22(8):708-728.

[11] Stafford, G. S. and Miles, H. (2013). Culture Traits, Strength, and Organizational Performance: Moving beyond Strong Culture, The Academy of Management Review, 13, (5), 546-558.

[12] Shahzad, K. Rana, G. Khan, F. and Shabbir, O. (2012). A framework for linking culture and improvement initiatives in organizations. The Academy of Enterprises, 2(1), 25-46.

[13] Stannack, P. (2006). Perspective on Employees Performance, Management Research News, 119 (4), 38-40.

[14] Tajfel, H. (1974). Social identity and intergroup behaviour. Social Science Information/surles sciences sociales, 13(2):65-93. http://dx.doi.org/10.1177/053901847401300204 